\title{
A MIGRAÇÃO DO SOFTWARE PROPRIETÁRIO PARA O SOFT- WARE LIVRE COMO PROCESSO PEDAGÓGICO
}

\author{
MIGRATION FROM PROPRIETARY SOFTWARE TO FREE SOFTWARE AS A \\ PEDAGOGICAL PROCESS

\section{LA MIGRACIÓN DE SOFTWARE PROPIETARIO A SOFTWARE LIBRE COMO UN PROCESO PEDAGÓGICO}

\author{
Anderson Fernandes de Alencar \\ Doutor e Mestre em Educação (USP), Bacharel e Licenciado em Pedagogia (UFPB). \\ Instituto Paulo Freire / Universitas Paulo Freire (UniFreire). \\ anderson.alencar@gmail.com
}

Moacir Gadotti Livre-docente (Unicamp), Doutor em Educação (Universidade de Genebra) e Mestre em Filosofia (PUC-SP). Graduado em Pedagogia e Filosofia. Universidade de São Paulo / Instituto Paulo Freire. gadotti@paulofreire.org

RESUMO: Este trabalho apresenta reflexões, aprendizagens e conclusões advindas da pesquisa realizada em nível de mestrado, na linha de filosofia e educação, cujo objetivo foi refletir acerca de uma proposta de migração do software proprietário para o software livre à luz de elementos teórico-práticos do pensamento de Álvaro Vieira Pinto e de Paulo Freire. O artigo inicia-se pela exposição dos objetivos, a metodologia e as fontes de informações utilizadas na pesquisa, seguindo pela apresentação das contribuições dos autores citados ao estado da arte das reflexões acerca da tecnologia, e a partir delas, expõe-se a gênese do movimento do software livre e as potencialidades de seu uso. A partir destas análises, evidencia-se um estudo de caso realizado em uma ONG de cunho educacional da cidade de São Paulo e destaca-se o processo de consulta aos sujeitos da experiência de migração, realizada por meio de questionários, bem como os resultados da sistematização deste instrumento. Por fim, conclui-se que a migração constitui-se em um processo pedagógico, de "descolonização da mente", e por isso demanda uma pedagogia coerente com princípios freirianos e as concepções de homem, mundo e sociedade defendidas, visando à emancipação dos sujeitos envolvidos no processo. Essa pedagogia veio a ser nominada de Pedagogia da Migração. PALAVRAS-CHAVE: Paulo Freire. Software Livre. Migração. GNU/Linux. Pedagogia.

ABSTRACT: This paper presents reflections, learnings and conclusions obtained from research conducted at master's degree, in philosophy and education, whose purpose was to reflect about a proposal of migration from proprietary software to free software based on theoretical-practical thinking of Alvaro Vieira Pinto and Paulo Freire. The article begins by presenting the objectives, the methodology and sources of information used in the research, followed by the contributions of the authors cited to the state of art of the studies about technology, and from them, exposes the genesis of the free software movement and the potential for its use. After that, the text discusses a case study, carried out in an educational NGO, located in the city of São Paulo and highlights the process of listening the participants, conducted through questionnaires, as well as the results of the systematization of this instrument. Finally, it is concluded that the migration is a pedagogical process, of "decolonization of the mind", and therefore based in a coherent pedagogy with Paulo Freire principles and conceptions of man, world and society defended, aiming at the emancipation of the subjects involved in the process. This pedagogy came to be named Pedagogy of Migration. KEYWORDS: Paulo Freire. Free software. Migration. Gnu/Linux. Pedagogy.

RESUMEN: Este artículo presenta reflexiones, aprendizajes y conclusiones obtenidas a partir de las investigaciones realizadas a nivel de maestría, en filosofía y educación, cuyo objetivo era reflexionar sobre la propuesta de la migración de software propietario a software libre a la luz de los elementos teóricos y prácticos del pensamiento Álvaro Vieira Pinto y Paulo Freire. El artículo comienza con la presentación de los objetivos, la metodología y las fuentes utilizadas en la investigación, seguida de la presentación de las contribuciones de los autores citados para los estudios acerca de la tecnología, y de ellos, se expone la génesis de movimiento del software libre y la posibilidad de su uso. A partir de estos análisis, se ha demostrado un estudio de caso realizado en una ONG de carácter educativo de la ciudad de São Paulo y destaca el proceso de consulta a los sujetos de la experiencia de la migración, llevada a cabo a través de cuestionarios, y los resultados de sistematización de este instrumento. Por último, se concluye que la migración es un proceso pedagógico, "la descolonización de la mente", y por lo tanto exigen una pedagogía con los principios freirianos y concepciones del hombre, mundo y de la sociedad, con el fin de defender la emancipación de los sujetos involucrados en el proceso. Esta pedagogía llegó a ser llamada Pedagogía de la Migración.

PALABRAS CLAVE: Paulo Freire. Software libre. Migración. Gnu/Linux. Pedagogia.

$\overline{\text { Artigo recebido em maio de } 2014}$

Aprovado em julho de 2014

Cad. Pes., São Luís, v. 21, n. 2, mai./ago. 2014 
A MIGRAÇÃO DO SOFTWARE PROPRIETÁRIO | Anderson Fernandes de Alencar e Moacir Gadotti

\section{1 | INTRODUÇÃO}

Acessar e saber utilizar criticamente as tecnologias da informação e da comunicação são pré-requisitos de uma "inclusão digital" emancipadora. Não basta ser um "apertador de botões". Hoje, não ter acesso às tecnologias da informação significa restringir poder e participação ativa e efetiva na construção de sociedades mais justas e igualitárias. Ela é condição para que todos, e não apenas uma minoria, sejam incluídos na chamada "sociedade da informação". É preciso ter acesso, mas não por quaisquer meios. O próprio processo de inclusão precisa lançar mão de recursos democráticos e participativos. Não é possível fazer "infoinclusão" pagando licenças de uso de softwares proprietários, apoiados em pressupostos de mercado que visam ao lucro, à reprodução e ampliação do capital e a concentração da riqueza. O software livre é uma alternativa a esse modelo e possibilita a geração de experiências de infoinclusão autossustentáveis. Ele carrega em seu bojo uma visão de mundo que advoga o compartilhamento da informação, o trabalho colaborativo, a luta contra os grandes monopólios e a luta pelo direito ao conhecimento no campo do direito autoral e das patentes, entre outras. O software livre é:

\footnotetext{
Um programa é software livre se os usuários possuem as quatro liberdades essenciais: 1 A liberdade de executar o programa, para qualquer propósito (liberdade 0); 2 A liberdade de estudar como o programa funciona, e adaptá-lo às suas necessidades (liberdade 1). Para tanto, acesso ao código-fonte é um pré-requisito; 3 A liberdade de redistribuir cópias de modo que você possa ajudar ao próximo (liberdade 2); $4 \mathrm{~A}$ liberdade de distribuir cópias de suas versões modificadas a outros (liberdade 3). Desta forma, você pode dar a toda comunidade a chance de beneficiar de suas mudanças. Para tanto, acesso ao código-fonte é um pré-requisito. (FREE SOFTWARE FOUNDATION, 2012).
}

Contudo, o uso do software livre pelo usuário iniciante na área da informática requer certos conhecimentos que, por vezes, são diferentes daqueles já conhecidos nos softwares proprietários, afinal tratamos de um hábito enraizado há quase trinta anos, desde o lançamento da primeira versão do MS Windows em 1985. A mudança, a migração, a transição de uma tecnologia para outra, não é algo simples de se fazer. Ela requer uma pedagogia coerente com os pressupostos filosóficos que deram origem ao software livre, de acesso irrestrito.

No intuito de dar conta deste desafio, realizamos uma pesquisa participante (BRANDÃO, 1981), em nível de mestrado, defendida na linha de filosofia e educação (ALENCAR, 2007), que teve por objetivo refletir acerca de uma proposta de migração do software proprietário para o software livre fundamentada em contribuições do pensamento do filósofo Álvaro Vieira Pinto e do educador Paulo Freire; isto é, como, a partir destes pensadores, poderíamos refletir o processo de migração tecnológica, e ainda ousar na proposição de uma nova metodologia a partir da sua releitura, no esforço de constituição de uma Pedagogia da Migração. Por essa razão, nossos objetivos específicos foram:

a) investigar o pensamento de Álvaro Vieira Pinto e Paulo Freire referente à tecnologia;

b) compreender as implicações políticas, econômicas, sociais e ideológicas do software livre no mundo contemporâneo;

c) apresentar a experiência de migração da ONG;

d) refletir a experiência de migração da ONG, identificando contribuições ao processo de migração para GNU/Linux.

A pesquisa consistiu, além de um estudo teórico, em um estudo de caso (a experiência de migração de uma ONG, de cunho educacional, na cidade de São Paulo) por meio do qual apresentamos sugestões, propostas e indicações concretas, unindo princípios freirianos à sua 
aplicação na experiência de migração desta organização. Nesse sentido, pretendeu-se, além de apresentar elementos teórico/práticos relevantes para uma proposta de migração, propor uma Pedagogia da Migração do software proprietário para o software livre. A pesquisa teve por objeto a migração para software livre em uma perspectiva freiriana.

Quanto à metodologia, o trabalho foi realizado inicialmente por meio de uma revisão bibliográfica e audiovisual da obra de Paulo Freire, valendo-nos da técnica do fichamento, buscando identificar nestas obras, referências ou reflexões acerca da tecnologia. Em seguida, foram extraídas e categorizadas, por meio de grandes temas, as expressões do educador. Na pesquisa, também foram consideradas as ideias de Álvaro Vieira Pinto sobre a tecnologia, a partir do livro publicado pós-morte intitulado "O Conceito de Tecnologia", dada a ligação deste com Paulo Freire e as implicações de seu pensamento na constituição da obra do educador.

Depois, foram realizadas leituras referentes ao software livre, no intuito de refletir acerca de suas contribuições ao estado da tecnologia no contexto atual e sobre a sua importância no campo político, econômico, filosófico, social e tecnológico.

No terceiro momento, envolvemo-nos em todo o processo de migração da ONG, documentando a experiência, contribuindo nas definições da equipe de migração, refletindo com o grupo, que dela participou, sobre a forma da experiência de incorporar, na sua totalidade, os pressupostos filosóficos de Paulo Freire e, ao mesmo tempo, envolvermos no processo de migração, como participantes. A documentação da experiência foi realizada por meio de anotações para salvaguardar o histórico do processo. Foram feitos levantamentos documentais como textos, fotos, relatos orais, registro de e-mails enviados no processo, gravação em vídeo dos eventos de maior relevância, conversas com os componentes da equipe de migração, depoimentos dos participantes da experiência, entre outros.

No quarto momento, foi enviado a mais de cinquenta pessoas da instituição um questionário com oito perguntas que objetivava identificar a "freirianidade" da experiência, os elementos que possibilitaram uma mudança de cultura, de pensamento e de ação, e ainda, no intuito de identificar as suas aprendizagens no processo, a relevância das equipes na migração, entre outras coisas. Os questionários foram sistematizados em tópicos que agrupavam as respostas dos migrantes.

A partir da experiência da instituição e dessa sistematização foi possível, relendo o processo, elencar elementos para uma Pedagogia da Migração para GNU/Linux, pedagogia que se fundamenta no referencial teórico do educador Paulo Freire (ALENCAR, 2007, p. 19-20).

Não acreditamos na transposição acrítica de experiências. Cada instituição é singular e deve pensar sua própria migração. A pesquisa oferece contribuições, aporte teórico-metodológico e elementos orientadores para a realização de experiências de migração que atuem pautados nos princípios filosóficos defendidos por Paulo Freire e seus contemporâneos, valorizando elementos que tornem essa migração mais humana, democrática e efetiva. Afirma Freire (1994, p. 61):

A sua grande preocupação não é, em verdade, ver criticamente o seu contexto. Inte-
grar-se com ele e nele. Daí se superporem a ele com receitas tomadas de emprésti-
mo. E como são receitas transplantadas que não nascem da análise crítica do próprio
contexto, resultam inoperantes. Não frutificam. Deformam-se na retificação que Ihes
faz a realidade. De tanto insistirem essas sociedades nas soluções transplantadas,
sem a devida "redução" que as adequaria às condições do meio, terminam as suas
gerações mais velhas por se entregarem ao desânimo e a atitudes de inferioridade.

Este artigo, por sua vez, objetiva socializar reflexões, aprendizagens e conclusões advindas da pesquisa realizada, consolidadas na dissertação defendida. 
O texto está organizado em cinco partes: na primeira parte tratamos das contribuições de Álvaro Vieira Pinto e Paulo Freire ao estado da arte das reflexões acerca da tecnologia; na segunda, apresentamos a gênese do movimento do software livre, junto a algumas potencialidades em seu uso; na terceira parte, evidenciamos o estudo de caso realizado em uma ONG de cunho educacional, da cidade de São Paulo; na quarta, destacamos o processo de consulta aos sujeitos da experiência de migração, bem como resultados da sistematização; por fim, concluímos, refletindo a migração como processo pedagógico, e defendendo a necessidade de uma pedagogia da migração que considere o humano, sua cultura e seus conhecimentos prévios.

\section{2 | A TECNOLOGIA NA OBRA DE ÁLVARO VIEIRA PINTO E PAULO FREIRE}

A contribuição de Álvaro Vieira Pinto e Paulo Freire para a reflexão acerca da tecnologia e de suas implicações, e para subsidiar teoricamente a experiência de migração da ONG, foi inestimável. Foram suas práticas e teoria que nos indicaram, quase sempre, o melhor caminho a seguir, buscando o ser mais, pelo qual Freire tanto lutou.

Álvaro Vieira Pinto nos propiciou construtos importantes para as nossas reflexões acerca da técnica e da tecnologia (ALENCAR, 2007, p. 23-33). Sua teoria, profunda e incisiva, nos levou a refletir sobre o papel das técnicas no mundo de hoje, sobre a influência da tecnologia sobre as sociedades e sobre as práticas cotidianas. O conceito de técnica como prática pertencente estritamente aos seres humanos, que pensam, que projetam, que refletem, que constroem, que agem, que refletem o feito, está presente na história humana desde os seus primórdios, isto é, não é uma novidade, algo que surgiu recentemente, mas são práticas que sempre acompanharam os seres humanos, por isso, a sua crítica tão veemente à chamada "sociedade tecnológica" (VIEIRA PINTO, [197-?], p. 146).

O filósofo também nos propiciou pressupostos para uma reflexão mais apurada acerca das atitudes que devemos evitar ou ter diante da tecnologia. Daí sua crítica ao embasbacamento e ao maravilhamento indevido diante dos aparatos tecnológicos. É ingênuo pôr-se diante das invenções em um modo tal de admiração, que simplesmente ofusque a nossa percepção quanto às dimensões subjacentes àquela tecnologia, como a ideológica. Este enebriamento muitas vezes é manipulado pelas classes dominantes no intuito de manter os oprimidos submissos e felizes por viverem em uma época tão maravilhosa (VIEIRA PINTO, [197-?], p. 41).

Vieira Pinto ainda contribuiu eficazmente para a construção desta proposta de migração ao reiterar a necessidade de rompermos com toda dependência tecnológica e defender uma tecnologia que seja considerada patrimônio da humanidade. Criar autonomia tecnológica no âmbito particular, no institucional ou para o próprio país é uma questão importante nas reflexões do filósofo. A dependência tecnológica tem uma estrutura similar à antiga estrutura, mas bem presente, de colônias e metrópoles da qual o Brasil foi vítima. Enquanto a colônia empobrece, a metrópole enriquece às custas da colônia que domina (VIEIRA PINTO, [197-?], p. 44). A dependência tecnológica só beneficia os detentores da tecnologia e elimina a possibilidade de produção de uma tecnologia estritamente nacional que possa até fazer frente a essa tecnologia exterior. O próprio movimento do software livre carrega uma dessas bandeiras na própria forma como o software é desenvolvido e compartilhado.

Associado a isso temos o forte movimento de democratização da informação, também bandeira do movimento do software livre, a que Vieira Pinto se referiu como uma tecnologia patrimônio da humanidade. A tecnologia entendida como uma construção coletiva pertence ao coletivo e não a particulares ou às grandes corporações. A privatização do conhecimento só interessa àquelas pessoas e instituições que visam à maximização de seus lucros às custas dos oprimidos, ao pas- 
so que o movimento de compartilhamento busca incluir indistintamente, permitindo a todos as mesmas condições de acesso à informação, à tecnologia e também à sua produção.

Paulo Freire foi uma referência fundamental na formulação da experiência de migração. Seu pensamento e sua prática deram grandes contribuições para o processo vivido na ONG (ALENCAR, 2007, p. 33-50). Ele contribuiu, de modo muito claro, com o processo, pela sua concepção de práxis, que associada à tecnologia, fez emergir o que defendemos como "práxis tecnológica" (FREIRE, 1984, 1992). Nesse contexto, essa "práxis tecnológica" impulsionava-nos para dois movimentos: para a reflexão constante sobre as ações/processo que foi explicitado em diversos momentos desta migração, em seus encontros, em suas fichas de avaliação, na escuta dos migrantes; e para o movimento de uma real apropriação e controle da tecnologia, que sempre deve ser crítica, reflexiva, e que se manifestou pelas formações e oficinas técnicas.

Um segundo ponto em que as contribuições de Freire foram decisivas para nosso trabalho diz respeito à finalidade dos usos que fazemos da tecnologia (FREIRE, 2000, p. 102). Tecemos reflexões acerca da necessidade de compreender o processo, muito mais que técnico, como um movimento de luta política e ideológica contra uma concepção hegemônica que nos foi imposta "docemente" sem que percebêssemos. A tecnologia deve ser fundada em princípios éticos e, portanto, deve servir como fim último à felicidade do homem. Para Freire, a tecnologia é uma poderosa ferramenta para reforçar as nossas lutas por outro mundo possível, como advoga o Fórum Social Mundial. A tecnologia, ainda nessa perspectiva, deve ser reinventada para atender às necessidades dos seres humanos (FREIRE, 1994, p. 139).

Por fim, destacamos a luta de Paulo Freire pela infoinclusão. Apesar de Freire nunca ter usado o termo, em diversas oportunidades a ela se refere e, de modo prático na Secretaria de Educação do Município de São Paulo, quando investiu na informatização de todas as escolas públicas do município (FREIRE, 1993, p. 107).

\section{3 | A REVOLUÇÃO DOS SOFTWARES LIVRES}

A pesquisa segue aprofundando reflexões acerca do software livre e da sua constituição como um movimento pela liberdade do conhecimento (ALENCAR, 2007, p. 51-57).

Historicamente, temos demarcado o nascimento na iniciativa do professor Richard Stallman, do Massachusetts Institute of Technology (MIT) nos anos 80, a partir da constatação de que a tecnologia, neste ínterim os softwares, começavam a ser privatizados. Resistente a essa privatização e a mercantilização destas tecnologias, inaugura um projeto chamado de GNU (GNU's not Unix), e ao redor deste, inicia-se uma comunidade de compartilhamento que retoma os ideais de liberdade dos softwares produzidos até então (STALLMAN, 2002).

A partir deste movimento inicial, temos a confluência de uma segunda iniciativa em direção similar, intitulada de "softwares de código aberto", visando maior aproximação destas iniciativas com as empresas.

No trabalho, também foram apresentadas razões filosóficas, técnicas e econômicas para a utilização dos softwares livres e suas limitações, que expomos a seguir:

a) razões de cunho filosófico: os princípios que embasam o software livre, torna-nos partícipes de uma comunidade de solidariedade: uma comunidade autossustentável; inaugura um novo fórum para ação democrática; amplia a possibilidade de infoinclusão; sistemas operacionais ilegais como dilema moral; a luta contra os monopólios; há sempre a possibilidade de "criar um novo caminho"; o software não devia ser propriedade de ninguém;

b) razões de cunho técnico: disponibilidade do código fonte; direito de redistribuir; direito de usar o software para qualquer fim; não somos reféns da tecnologia proprietária; não estamos 
sujeitos ao ciclo da obsolescência do hardware; outras razões - robustez, segurança, flexibilidade, qualidade, estabilidade, confiabilidade/transparência, disponibilidade, privacidade, escalabilidade, interoperabilidade;

c) razões de cunho econômico: não estamos presos a um único fornecedor; não há preocupação com as pressões do mercado; custo inicial próximo do zero; suporte abundante e gratuito; condições de empregabilidade;

d) e como limitações: incertezas quanto ao desenvolvimento e continuidade de projetos; possíveis problemas ligados à propriedade intelectual; dificuldade em localizar e saber o estado de um software livre; interface para o usuário não é uniforme; instalação e configuração podem ser difíceis; poucos ou caros profissionais disponíveis; fragilidades humanas (HEXSEL, 2002, p. 12-21).

$\mathrm{Na}$ pesquisa, o software livre revelou-se como a melhor opção técnica, bem como político-ideológica para a ONG em questão. O software livre é uma proposta contra-hegemônica aos modelos centralizados de produção e dos processos; é uma contraproposta à dependência tecnológica, ao enclausuramento do conhecimento, a monopolização dos softwares, que pertencem à humanidade; é, além de muitas outras coisas, uma contraproposta à mercantilização das relações. Um movimento de generosidade intelectual.

O software livre pode ser considerado, na nossa concepção, como um movimento planetário, com bandeiras de lutas próprias e que não tem localização geográfica porque está em todo o mundo, está na rede, na internet, na ONG mencionada etc.

\section{4 | A MIGRAÇÃO PARA SOFTWARE LIVRE DA ONG: um estudo de caso}

Mesmo compreendendo que a migração, por ser um processo de transformação cultural, não se dá "do dia para a noite", podemos dizer que a experiência teve suas ações concluídas. Atualmente, o que a organização vivencia, é a manutenção do processo realizado ou a implementação de novas tecnologias em substituição àquelas obsoletas.

Durante a pesquisa, tivemos a oportunidade de atuar na construção e execução da proposta, tanto como parte da equipe de migração, quanto como migrante. Para o relato, optamos por manter a ordem cronológica dos eventos para que o processo fosse compreendido em suas sucessivas ações, sendo expostos os avanços e as fragilidades da experiência (ALENCAR, 2007, p. 88-94).

A migração da ONG, partindo de referências tais como o "Plano de Padronização do Ambiente e Migração para Software Livre" (BRASIL, 2005b) e o "Guia Livre: Referência de Migração para Software Livre do Governo Federal" (BRASIL, 2005a), foi organizada em cinco fases: a primeira contou com a sensibilização/reflexão de natureza filosófico-política acerca do conceito de software livre, elaboração do plano de migração, encontro de avaliação deste plano e constituição da equipe de migração.

A segunda tratou da construção de material didático acerca do pacote de escritório BrOffice. org (Writer, Calc e Impress) / Gimp, instalação do BrOffice.org nas máquinas MS Windows e oficinas técnico-pedagógicas. A terceira, do encontro de avaliação da segunda fase, desinstalação do MS Office (Word, Excel, Powerpoint, Access) e instalação do Mozilla Firefox (navegador de internet) / Thunderbird (gerenciador de e-mails), além da construção de material didático acerca da distribuição Kubuntu. A quarta foi iniciada com um evento de abertura da fase, desinstalação do MS Windows e instalação/oficinas de Kubuntu, versão GNU/Linux para desktops. A quinta contou com entrevistas, por meio de questionários, realizadas pelo pesquisador. 
A MIGRAÇÃO DO SOFTWARE PROPRIETÁRIO | Anderson Fernandes de Alencar e Moacir Gadotti

Todo o processo de migração da ONG foi pensado, nos seus fundamentos e na sua estrutura, pela equipe de migração da instituição. Esta não foi uma ação isolada da equipe de informática, mas uma ação integrada com diversos outros grupos/pessoas que se dispuseram a colaborar no processo. Tirar a primazia da migração para GNU/Linux da "mão dos técnicos" é uma importante contribuição da experiência da ONG. A equipe de migração era composta de um pedagogo e duas pedagogas, uma fotógrafa, um estudante secundarista e duas jornalistas. Foi esta equipe multidisciplinar que conseguiu atingir de modo muito pertinente os objetivos referentes à sensibilização/conscientização, como aqueles de cunho estritamente técnico.

Não queremos desmerecer o papel dos técnicos, que é imprescindível, mas é necessário reforçar que processos de migração, de transformação cultural, não podem prescindir da dimensão pedagógica. E na perspectiva aqui defendida, pautados em uma educação emancipadora, e não bancária (FREIRE, 1970), isto é, a migração, antes de ser um processo técnico, é um processo humano, e de humanos, partícipes e sujeitos do seu próprio processo de migração. O ser humano deve ter um papel central na migração para GNU/Linux; temos que humanizar a migração.

\section{5 | A DESCOLONIZAÇÃO DAS MENTES: os migrantes dizem a sua palavra}

No intuito de reunir outros elementos para a reflexão acerca de uma Pedagogia da Migração e de conseguir "captar o olhar", não somente do pesquisador ou da equipe de migração quanto ao processo, foi preparado um questionário para que aqueles que participaram da experiência, em qualquer uma de suas fases, pudessem apresentar suas ideias. O questionário foi respondido por 32 migrantes da instituição (ALENCAR, 2007, p. 129-132).

O instrumento possuía oito questões, sendo a última de múltipla escolha com uma questão aberta. As perguntas eram: 1) O que você aprendeu, nesse processo de migração, sobre o software livre? 2) Quais os motivos que lhe impulsionaram a migrar para software livre? 3) Você teve algum tipo de dificuldade no seu processo de migração? 3.1) Se sim, quais foram, em que momento surgiram e o que contribuiu para que você superasse a (s) dificuldade (s)? 4) Você encontrou facilidades? Quais? 5) A migração para software livre envolve dimensões políticas, técnicas e pedagógicas. Você concorda? Por quê? Além dessas, você identifica outras? 6) A experiência de migração do Instituto Paulo Freire foi realizada de acordo com os princípios freirianos. Você concorda? Por quê? Em que momentos esses princípios ficaram explícitos? 7) Você estaria disposto (a) a utilizar softwares livres e o sistema operacional completo (Linux) em outros espaços, como sua casa? 8) Na sua opinião, qual foi a contribuição das equipes citadas abaixo para o processo de migração do Instituto Paulo Freire?.

A sistematização destes questionários trouxe contribuições relevantes para outros processos de migração para GNU/Linux, além de apresentar as potencialidades e as fragilidades da experiência da ONG.

Com o questionário, buscávamos identificar quais os elementos que, na experiência da ONG, possibilitaram aos migrantes uma mudança de cultura, uma ruptura com a sua forma antiga de pensar, sua superação e o desenvolvimento de um novo olhar, isto é, o que propiciou a descolonização da mente daqueles migrantes.

As respostas foram de várias naturezas. A diversidade de pessoas, de histórias de vida, de aproximações positivas ou negativas com o software livre, todos estes são elementos que não podem ser desconsiderados em uma análise como esta.

Aprendemos de Freire e do processo: a mudança não pode ser imposta, dada em um ato autoritário. As pessoas, nessa circunstância, não mudam, elas simplesmente se adaptam, se acomodam à nova situação da forma mais confortável possível. Não há mudança cultural aí. $\mathrm{Na}$ 
experiência relatada, essas mudanças se deram em momentos e situações-limite bem distintas. Para uns, o momento de sensibilização foi o estopim da ruptura; para outros, foi uma oficina de um programa de computador, para alguns foi o direito a falar, que the foi dado em um encontro; outros, ainda, foi o espaço que Ihe foi dado para opinar em uma questão estritamente técnica; e, por fim, para outros foi o carinho, a atenção, a paciência, o cuidado com que foram tratados (as) em um momento de suporte que geraram mudança. As experiências de ruptura, de descolonização das mentes são múltiplas.

Destacamos a sistematização das respostas dadas à questão 6, que tratou da freirianidade da experiência, na qual os migrantes informaram por que ou em que medida a migração foi freiriano ou não:

1) a migração foi dialógica, sem imposições, todos puderam dizer sua palavra;

2) a migração foi democrática, compartilhada, construída coletivamente;

3) a migração expôs com clareza o caráter político da migração;

4) a migração respeitou o conhecimento prévio dos envolvidos;

5) a migração fez práxis em todo o processo;

6) a migração respeitou a realidade, o tempo e cultura dos projetos da ONG e de cada pessoa;

7) a equipe de migração foi amorosa no suporte. Foi paciente, compreensiva, preocupada em todo o processo com a pessoa;

8) a migração fez a leitura de mundo da realidade da ONG (ALENCAR, 2007, p. 156-159).

\section{6 | A MIGRAÇÃO COMO PROCESSO PEDAGÓGICO}

Mudar cultura não é algo que se faz de fora para dentro, "por decreto", como diria Freire, nem muito menos tem data certa para acontecer. O "cair da ficha", a descolonização da mente ou a conscientização é um movimento (momento) muito particular do sujeito em interação com os objetos, com o conhecimento, com a experiência tácita. O que a equipe de migração fez foi lançar questões, situações problematizadoras que provocassem a reflexão dos migrantes sobre suas próprias práticas sociais, humanas, políticas, e assim pudessem reavaliar sua própria prática, seus conceitos, suas crenças, sua forma de enxergar o mundo, a sociedade e a si mesmo.

A partir da análise dos referenciais teóricos, do estudo de caso e dos questionários sistematizados, tiramos duas conclusões centrais que ora apresentamos como as mais relevantes: 1 ) O papel da formação em processos de migração para software livre; e 2) A migração como um desafio eminentemente pedagógico (ALENCAR, 2007, p. 207).

Partindo do pressuposto de que todas as ações e atividades humanas são processos formativos, entendemos que a experiência de migração para GNU/Linux da ONG foi um grande processo de formação. Todos aprendemos ao ensinar, e todos ensinamos ao aprender. Não houve verticalismo.

Relembramos um momento importante quando, em diálogo sobre o nome que daríamos às reuniões que estávamos promovendo na migração com as equipes, nos havia sido sugerido o nome "Encontro de Formação". Afinal, todos aqueles encontros eram sempre espaços de formação, que não implicavam na estrutura professor-alunos, mas em um círculo de cultura através do qual todos aprendiam e todos ensinavam, no qual não havia hierarquia de superior-inferior ou dos que sabiam e dos que não sabiam e estavam ali para saber. Era um espaço para um diálogo sincero, horizontal e autêntico. Consideramos o nome sugerido tão adequado, que acabamos por adotá-lo em praticamente todas as atividades conjuntas da migração. Era o "Encontro de Formação para Discussão do Plano de Migração", o "Encontro de Formação para Avaliação da 2a Fase da Migração", rememorando constantemente desta dimensão do processo de migração. 
Eram encontros formativos: as nossas reuniões, as oficinas, a avaliação, as reuniões da equipe de migração, os papos de corredor e no almoço, os conflitos, as reuniões com as equipes da instituição, as consultas às equipes, a paciência com relação aos convites, o respeito ao tempo cronológico e cognitivo de cada equipe, a construção dos materiais didáticos, os intensos debates sobre o formato e o conteúdo, sobretudo o suporte. O suporte - auxílio técnico na solução de problemas e dificuldades - garantido a todos que vivenciaram o processo da migração foi certamente um dos espaços mais frequentes e mais intensos de formação, tanto para quem oferecia a mão quanto para quem a recebia. As oficinas e os eventos eram momentos pontuais no processo, já o suporte, o momento para retirar dúvidas, ensinar um novo procedimento, ajudar a localizar um documento no momento de desespero, solucionar um problema físico no computador, todas essas ações eram constantes em toda a migração, requeriam muita paciência, generosidade e tranquilidade da equipe de suporte para atender a todas as demandas.

Esse trabalho de suporte, em grande parte das instituições, é estritamente feito por técnicos, que não possuem formação pedagógica. A experiência vivida revela a necessidade dos técnicos de informática possuírem formação pedagógica. $O$ trabalho desses técnicos, em uma perspectiva dialógica e emancipadora, não pode dar-se de forma alheia à dimensão pedagógica. Eles possuem um saber e uma experiência, mas, muitas vezes, não conseguem compartilhar e aprender em conjunto. Como ensinar sem formação alguma na área pedagógica? Não se pode ensinar de qualquer forma. Existem teorias do conhecimento desenvolvidas sobre o processo de ensino e aprendizagem, tal como a desenvolvida por Paulo Freire no seu livro "Pedagogia da Autonomia", que devem ser estudadas, refletidas e postas em prática. A atividade de suporte é imprescindível para garantir o "sucesso" da experiência de migração. Fundamentados no princípio da impessoalidade advindo da área da Administração, os técnicos acabam por criar cada vez mais intermediários entre eles e o migrante. São telefones, computadores, manuais, apostilas que, nesse contexto, só servem para tornar a relação entre migrante e técnico mais distante, mais fria, não humanizadora (no sentido de promover a possibilidade de aprendizado, reflexão, proposição). O ser humano é visto como máquina que, ao receber uns comandos, vai agir conforme a programação. Precisamos superar esta visão (ALENCAR, 2007, p. 208).

Saber como falar, como se portar, como "abordar" o migrante, ser paciente, são atitudes pedagógicas que devem ser levadas em consideração no momento do suporte.

Compreendemos, a partir da práxis vivida, que a experiência de migração é um processo eminentemente pedagógico. Não é possível realizar a migração em uma perspectiva emancipatória, autônoma se não a compreendemos como um espaço formativo.

A experiência da ONG não teria acontecido da forma que aconteceu, se os educadores não fossem sujeitos desse processo. Foram eles que tornaram humana essa experiência de migração, que a aproximaram da realidade de cada pessoa, de cada equipe, que prepararam materiais com uma linguagem adequada para a compreensão dos migrantes, que idealizaram a metodologia de todas as oficinas, que pensaram as linhas gerais de todo o processo. Aprendemos, portanto, que a experiência de migração para software livre é, em grande medida, uma experiência pedagógica, e como processo pedagógico pressupõe uma pedagogia, um caminho de orientação, pressupõe desaprender determinados movimentos impregnados em nós, construir novos saberes e novas práticas.

Como dissemos, não estamos querendo desmerecer o papel dos técnicos na migração para GNU/Linux, mas queremos tão somente devolver ao lugar de justa pertença os educadores na migração. A experiência na ONG foi rica, na nossa concepção, porque constituiu uma equipe multidisciplinar com pelos três educadores de formação. Eles foram um ganho qualitativo da equipe de migração, da migração em si. A própria proposta de migração só foi possível de ser construída 
A MIGRAÇÃO DO SOFTWARE PROPRIETÁRIO | Anderson Fernandes de Alencar e Moacir Gadotti

graças a essa equipe de migração.

Por fim, insistimos que migrar não é um processo fácil. Paulo Freire deu, e tem dado, pela atualidade do seu pensamento, significativas contribuições de como realizar esse processo do modo mais pedagógico, respeitoso possível por meio de categorias como diálogo, construção democrática, esperança, paciência, luta, resistência, entre outras que embasaram este trabalho e toda esta experiência de migração, inspirando uma verdadeira Pedagogia da Migração (ALENCAR, 2007, p. 210). 
A MIGRAÇÃO DO SOFTWARE PROPRIETÁRIO | Anderson Fernandes de Alencar e Moacir Gadotti

\section{Referências}

ALENCAR, Anderson Fernandes de. A pedagogia da migração do software proprietário para o livre: uma perspectiva freiriana. 2007. Dissertação (Mestrado em Educação) - Faculdade de Educação, Universidade de São Paulo, São Paulo, 2007. Disponível em: <http:// www.teses.usp.br/teses/disponiveis/48/48134/tde08112007-150130/>. Acesso em: 9 jul. 2014.

BRANDÃO, Carlos Rodrigues. Pesquisa participante. São Paulo: Brasiliense, 1981.

BRASIL. Guia livre: referência de migração para software livre do Governo Federal. Brasília, DF, 2005a. Disponível em: <http://is.gd/b9jzzV>. Acesso em: 6 jan. 2014.

BRASIL. Plano de padronização do ambiente e migração para software livre. Brasília, DF, 2005b. Disponível em: <http://is.gd/a39B9O>. Acesso em: 6 jan. 2014.

FREE SOFTWARE FOUNDATION. O que é software livre?. 2012. Disponível em: <http://www.gnu.org/philosophy/free-sw.pt-br.html>. Acesso em: 6 jan. 2014.

FREIRE, Paulo. A máquina está a serviço de quem? Revista BITS, [S.I.], p. 6, maio 1984.

Educação como prática da liberdade. Rio de Janeiro: Paz e Terra, 1994.
. Pedagogia da esperança: um reencontro com a pedagogia do oprimido. Rio de Janeiro: Paz e Terra, 1992. $245 \mathrm{p}$.

. Pedagogia da indignação: cartas pedagógicas e outros escritos. São Paulo: UNESP, 2000.

. Pedagogia do oprimido. Rio de Janeiro: Paz e Terra, 1970. 218 p.

Política e educação: ensaios. São Paulo: Cortez, 1993. 119 p.

HEXSEL, Roberto A. Propostas de ações de governo para incentivar o uso de software livre. Curitiba, 2002. Disponível em: <http://is.gd/qdMMJZ>. Acesso em: 6 jan. 2014.

STALLMAN, Richard. Free software, free society: selected essays of Richard M. Stallman. Boston: Free Software Foundation, 2002. Disponível em: <http:// notabug.com/2002/rms-essays.pdf>. Acesso em: 6 jan. 2014.

VIEIRA PINTO, Álvaro. O conceito de tecnologia. Rio de Janeiro: Contraponto, [197-?]. v. 1. 